\title{
Ca isotope and trace element evidence for non-monomer impurity incorporation during calcite growth
}

\author{
JeNNIFER V. Mills ${ }^{1 *}$, Holly A. BARNHART ${ }^{2}$, DONALD \\ J. DEPAOLO ${ }^{3}$, LAURA N. LAMMERS ${ }^{3}$ \\ ${ }^{1}$ Department of Environmental Science, Policy, and \\ Management, University of California, Berkeley \\ (*correspondence: jennifer.mills@berkeley.edu) \\ ${ }^{2}$ Division of Geological and Planetary Sciences, Caltech \\ ${ }^{3}$ Energy Geosciences Division, Lawrence Berkeley National \\ Laboratory
}

Impurity ion and isotope partitioning into carbonate minerals provide a window into the molecular processes occurring at the fluid-mineral interface during crystal growth. Existing ion by ion models for classical calcite growth generate testable predictions for stable isotope fractionation and trace element distribution behavior in the presence of impurities. Here, we investigate calcite growth inhibition, calcium isotope fractionation, and impurity partitioning in the presence of two cations with starkly contrasting compatibility, magnesium and manganese, to test and extend the classical ion by ion framework for calcite growth

Independent seeded Mn-calcite and Mg-calcite growth experiments were run under different fluid $\mathrm{Me} / \mathrm{Ca}$ ratios $(\mathrm{Mn} / \mathrm{Ca} 0.001-0.15 ; \mathrm{Mg} / \mathrm{Ca}=0.01-2.5)$ using a chemostat reactor. $\mathrm{Mg}$ growth rate inhibition is log-linear, consistent with kink blocking due to slow desolvation of the $\mathrm{Mg}^{2+}$ aquocomplex relative to $\mathrm{Ca}^{2+}$. Mn exhibits much stronger loglinear growth rate inhibition even at very low $\mathrm{Mn}$ concentrations (fluid $\mathrm{Mn} / \mathrm{Ca}=0.001-0.05$ ). At higher $\mathrm{Mn}$ concentrations, inhibition lessens and rates increase slightly when solid phase $\mathrm{Mn} / \mathrm{Ca}>1 . \mathrm{Mn}$ is readily incorporated into the calcite lattice, with large partition coefficients $\left(\mathrm{K}_{\mathrm{d}}\right.$ 6-20) inversely correlated to growth rate. For both $\mathrm{Mn}$ and $\mathrm{Mg}, \mathrm{Ca}$ isotope fractionation is largely independent of impurity concentration (and thus growth rate). This suggests that the presence of $\mathrm{Mn}$ or $\mathrm{Mg}$ does not significantly change the relative rates of $\mathrm{Ca}$ attachment and detachment at kink sites, which is predicted by the classical ion by ion model during kink blocking. However, the large Mn partition coefficients cannot be explained by desolvation rate-limited attachment of $\mathrm{Mn}^{2+}$ at the kink. Instead, we propose that $\mathrm{Mn}$ inhibits calcite growth by a novel kink blocking mechanism involving ion pair or polynuclear cluster addition, kinetically limited by carbonate ion re-orientation to attach at the kink site. These findings point to a hybrid mechanism of calcite growth whereby $\mathrm{Ca}$ incorporates largely as a free ion at kink sites while $\mathrm{Mn}$ is incorporated via non-monomer attachment. 